\title{
EMOTIONAL AND PHYSICAL IMPACT OF LIGHTING QUALITY PARAMETERS AND CHARACTERISTICS ON HUMANS IN DIFFERENT VISUAL ENVIRONMENTS
}

\author{
N̦ikita KOČANOVS ${ }^{1}$, Raja KOČANOVA ${ }^{2}$, \\ Olesja BOGODISTAJA ${ }^{3}$
}

\author{
${ }^{1,2}$ Institute of Civil Engineering and Real Estate Economics, FEEM, Riga Technical \\ University, Kalnciema Street 6, Riga, LV-1048, Latvia \\ ${ }^{3}$ Arco Real Estate, SIA, Blaumana Street 5a-1, Riga, Latvia, LV-1011 \\ Corresponding authore-mail: Nikita.Kocanovs@rtu.lv
}

\begin{abstract}
The publication presents the results of the analysis of the issues related to lighting quality parameters and characteristics, its impact on human productivity, activities, safety, well-being, comfort, perception, behaviour and health in different visual environments (office, home, educational, industrial working place, urban environments). Studies show that lighting, its planning and qualitative settings, is a significant indoor environmental quality, energy efficiency and sustainability parameter, and plays an important role in the urban environment.
\end{abstract}

Keywords: Design, lighting, quality, real estate, visual environment planning.

\section{INTRODUCTION}

Throughout the last 20 years, lighting technologies have been constantly developing and the industry brings to the market more and more different solutions for the light sources and applications which are integrated into real estate and urban projects and affect visual environment and humans in this environment. Lighting is becoming a tangible part of economic value and qualitative component of real estate projects.

The assignment of this paper is to identify how lighting systems in visual environment impact social aspects of a real estate project.

Nowadays in the century of global urbanization, industrial revolution and changing environmental conditions the majority of big city inhabitants, residents of densely populated areas and people in general have started to pay more attention to better quality of life. Today the person has become more able to discriminate between the resources that he or she consumes, more able to assess the quality of products and services, what is more, the person has become more responsible for one's health in general, that is, more demanding in everything that in some way can influence personal comfort and well-being.

People spend incredibly much time of their productive lives in closed spaces with insufficient quantity of daylight. Basically, they spend their time at work, 
exposing their eyes to various visual loads which have generated a higher demand for qualitative artificial light.

It is a proven fact that $80 \%$ of the perception of the environment is visual perception. Vision is based on light; the eye is curious; it requires the light to be able to see. Therefore, it is possible to state, that lighting quality parameters play the key role in the process of visual perception. Entering the room our view checks it in terms of the direction of light and it tells us about the premises, its form, colors, architecture, interior, decorations, etc. Good lighting makes visual process easy and pleasant.

\section{LIGHTING QUALITY PARAMETERS AND CHARACTERISTICS}

For a long time, before people were able to use artificial light, natural daylight was the only light available. Modern lighting concepts combine both light sources for our improved well-being and health.

Numerous studies have been done regarding the effect of light on humans. The research in this field has proved that a poor quality of lighting can really cause fatigue, overwork, and discomfort, as well as reduce efficiency and attention. On the physical level, the impact of bad lighting on the visual analyzer can provoke the migraine attack. Light affects not only the vision, but also the biorhythms. Natural sunlight increases good mood, comfort and efficiency. A short light day in winter, on the contrary, reduces productivity. This is due to the presence of a photosensitive photo pigment in the visual system.

The quality of lighting is used to be valued according to characteristics based on the functions and effects of lighting in architecture and visual planning design, where the following aspects are most important:

Light for visual functions - ensures unimpaired vision which is glare-free and easy on the eyes;

Light with a biological effect - supports the circadian rhythm, has an energizing or relaxing impact;

Light used for emotional effect - enhances architecture and space, shaping it and improving the aesthetic impact.

Lighting quality parameters which determine the level of comfort, physical and emotional well-being as well as aesthetics in the particular environment are the following:

Sufficient light level. "The basis for any lighting installation is the quantity of light available for a specific visual task in a given situation. A set of fixed rules for overall illuminance levels as laid down in the standards for the lighting. International guidelines for illuminance levels range in values from $20 \mathrm{~lx}$ to 2000 lx. The recommended illuminance levels are mainly a consequence of the degree of difficulty of the visual task in contrast to the immediate environment, whereby extremely detailed visual tasks, where there is little contrast to the surrounding area, require the highest illuminance levels" (Ganslandt \& Hofmann, 1992).

Effective modeling. "Besides planning the lighting levels which are to be produced by luminaires, the lighting designer has to plan the lighting layout in 
accordance with the architectural design. The range of planning possibilities extends from harmonizing luminaires with available structural systems to selecting luminaires that will have an active influence on the overall visual appearance of the space. Depending on the specific lighting project, there may be a number of conditions that determine the lighting layout. The lighting layout should not be based entirely on technical or functional conditions; in spite of all the preconditions there is wide scope for arranging the luminaires in accordance with the design concept. The lighting should not be confined by purely technical considerations, but also take into account the aesthetics" (Ganslandt \& Hofmann, 1992).

Harmonious light distribution. "Excessive brightness differences are visually tiring and reduce the sense of well-being because the eyes are constantly required to adapt. But just as unpleasant as excessive contrasts are negligible differences in luminance which can quickly make a room appear monotonous. The best solution is a harmoniously balanced distribution of brightness in which the luminance of visual objects allows them to be clearly distinguished and differentiated against their background. With regard to safety, DIN EN 13201 requires uniform illumination of the road surfaces of thoroughfares and the avoidance of dark zones. Major differences in brightness should also be avoided indoors; this allows any hazards to be spotted in good time, e.g. in industrial facilities. Accordingly, the European standard DIN EN 12464-1 also recommends a balanced distribution of luminance levels which significantly aids visual performance and visual comfort in indoor work places." (licht.wissen 01, 2016)

Prevention of glare. "Glare impairs visual conditions and causes fatigue and reduced concentration in the long term. It is important to limit glare in order to avoid errors and accidents in the work place and on the road." (licht.wissen 01, 2016).

"An essential feature of good lighting is the extent to which glare is limited. There are two aspects to glare: the objective depreciation of visual performance, and the subjective disturbance felt by individuals through excessive luminance levels or stark contrasts in luminance levels within the field of vision. In the case of objective depreciation in visual performance the term physiological glare is applied. In this case the light from a glare source superposes the luminance pattern of the visual task, thereby reducing visibility.

"If the glare source is not the cause of a reduction in visual performance, but merely a subjective interference factor the term discomfort glare is used. Discomfort glare occurs when an individual is involuntarily or unconsciously distracted by high luminance levels within the field of vision. (Ganslandt \& Hofmann, 1992)".

Colour temperature. "Humans experience an environment not only through light and shadow, but also through color. The light color of a lamp also determines the spatial impression and is an important criterion in the planning of biologically effective lighting. The light of each light source has its own so-called light (or luminous) color. It is described by its color temperature, measured in Kelvins (K). The higher the temperature value, the cooler white the light color. 
Color temperature also has a non-visual effect. The light color also influences people's circadian rhythm. It is therefore an important criterion in the planning of biologically effective lighting based on natural daylight" (licht.wissen 01, 2016).

Colour rendering. "Light and color determine the "climate" of a room. For our own sense of well-being, it is important that the colors of the world around, and especially human skin, are rendered as realistically as possible. Good color rendering is an important quality feature of artificial lighting - and crucial in certain areas. The impression of color is determined by the interaction between the color of the observed objects (equals their spectral reflectance levels) and the spectral composition of the light. The general color rendering index $R_{\mathrm{a}}$ was developed to describe the qualities of color reproduction (color rendering index, CRI). The best $R_{\mathrm{a}}$ value is 100: this renders all colors naturally. The lower the $R_{\mathrm{a}}$ value, the worse the colors of the illuminated object are rendered." (licht.wissen 01, 2016)

The above-described parameters and characteristics refer to the quality of lighting. "Good lighting" is the lighting that meets all or nearly all quality characteristics.

\section{EMOTIONAL AND PHYSICAL IMPACT OF LIGHTING QUALITY PARAMETERS AND CHARACTERISTICS ON HUMANS}

Within the current research, the authors aim to answer the question "How do lighting quality parameters and characteristics impact humans in different visual environments?"

Materials of various scientific publications, studies and experiments in the fields of lighting, lighting industry and lighting design for the last 20 years (19962006) were selected and used for the analysis.

The result shows that the analyzed materials focus on different aspects of qualitative parameters and characteristics of lighting, but at the same time, they refer to different aspects of the impact on humans. The aspects mentioned can be split into two major groups: physical effect and emotional effect.

Physical effect is any consequence of some cause that is related to the material world.

Nowadays people spend most of their time in enclosed premises with artificial light. Many components of natural light spectrum that are important for our health are lost while passing through the glass. The light therapist Alexander Wunsch thinks that a man in the course of evolution has adapted to the spectrum of solar radiation and for good health (one of the basic needs?) it is necessary to receive a full spectrum. People compensate the lack of sunlight with walks in the parks, along the beach or relaxing on the balcony. For the first time, the effect of seasonal disorder was described by Dr. Normann Rosenthal (1984). Later an experiment was conducted among the inhabitants of Norway where polar night lasts for 49 days per year. People who live in such conditions often feel tired, they find it difficult to wake up and get to work or do anything, and many suffer from depression and apathetic conditions. 
Observations show that there is a specific relationship between lighting and productivity, visibility, behavior and health. They also show that natural lighting is always more favorable and convenient for all usual activities.

Alexander Wunsch studied the influence of different types of light on the human and came to the conclusions that any deviation from the natural light spectrum carries harmful potential for health (Wunsch, 2006). Scientists have been interested in this issue for a long time and many experiments have been carried out in this field.

In 1973, John Ott inspected two groups of children who worked in rooms without windows. In one room, the lighting was as close to the natural as possible due to the use of full-spectrum lamps and in another one only fluorescent lamps were used. As a result children who worked in the room with fluorescent lamps were at first hyperactive and then became very tired and lost the ability to concentrate; high blood pressure was also recorded.

Recently Alexander Wunsch tested a number of modern artificial light sources with regard to the biological effect they exert on humans in comparison to natural light. Professor came to the conclusion that incandescent lamp was the closest to the natural spectrum. The results of such studies rarely become known widely to the public. The fact is that most people do not understand much about these issues. In addition, the environment and its gifts in different cultures are valued differently. For most of us, light is such a habitual accompaniment of our life that we do not think about its various properties that affect physical aspects of our life (Wunsch, 2006).

Emotional effect is a relatively short physiological process, motivating and regulating activity, reflecting the subjective significance of objects and situations, and represented in the form of experience.

One of the most acute problems of the modern world is the general human body and brain overload and, as a consequence, the negative psycho-emotional condition that entails serious health problems. Stresses exacerbate this harmful effect. In addition, uncertainty, fear, doubt spoils mood and consequently, the desire to do anything.

Humans do not notice that they perceive light as a usual circumstance like oxygen, until they feel discomfort, for example, when the light is too bright. A great number of people do not realize that they feel tired in their workplace because of poor lighting, as this is not always so obvious. Professionals discuss general illiteracy in questions concerning lighting quality including the discussions about the need to discover emotional effects of lighting.

In any project whether it is an apartment, a shop or an office, lighting noticeably determines the atmosphere and the feeling of the visual environment. Since light effects are perceived subconsciously, people often do not realize where this or that feeling comes from. Those who use light consciously receive a tool for modeling the sense of safety that is especially valuable in places with a depressing atmosphere, for example, in tunnels. A lot of people are not able to explain the phenomenon of light, but they feel an effect of it as soon as it refers to their feelings. 


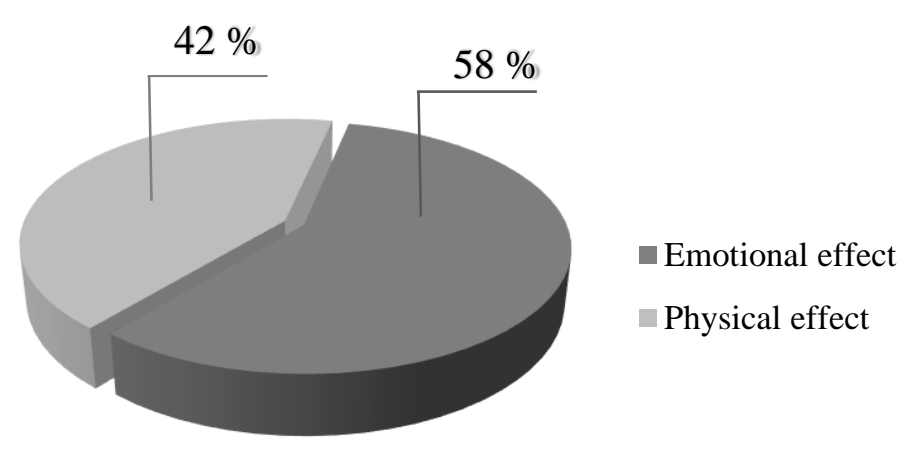

Fig. 1. Ratio of references to the physical and emotional effects of lighting in the reviewed studies.

Analyzed studies mainly refer to the emotional effect of lighting quality parameters and characteristics on humans in different visual environments, which means that lighting quality parameters have an important influence on human emotions. Real estate developers should take this fact into consideration in the course of planning of visual environment of the project.

Emotional effect consists of the following parameters mentioned in the analyzed materials:

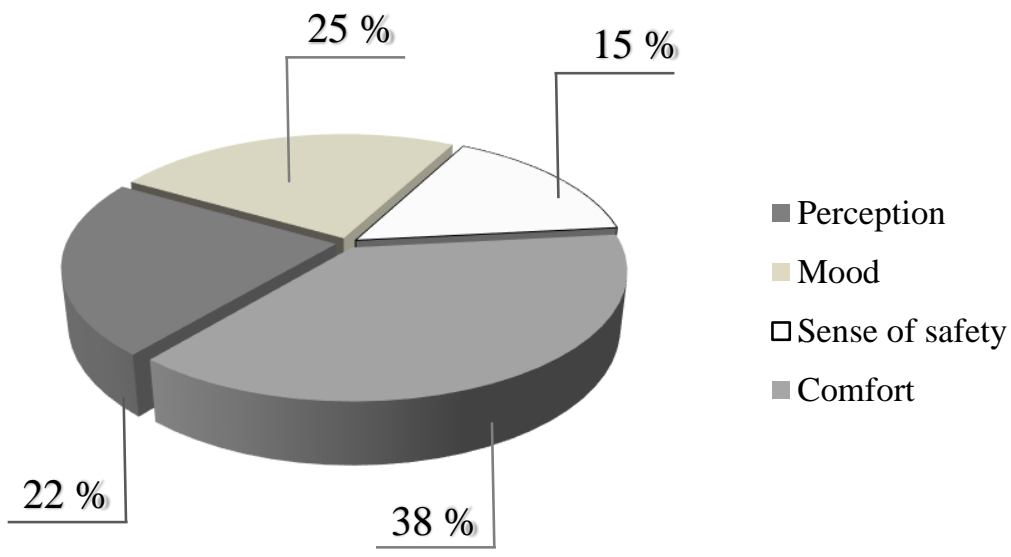

Fig. 2. Ratio of references to the emotional effects of lighting such as perception, mood, sense of safety and comfort in the reviewed studies.

Perception is a "neurophysiological processes, including memory, by which an organism becomes aware of and interprets external stimuli" (Perception, n. d.). About $80 \%$ of the surrounding perception is provided by the possibilities of our vision. Sufficient quantity and quality of light are the key factors of its correct perception. Human possibilities to recognize the shapes of objects, colours, people, and potential dangers vary depending on the illumination level, the time of its exposure and colour. Colour is one of the main characteristics of the light environment that determines the aesthetics of lighting, the emotional impact of the 
environment on a person. The dynamics of lighting is characterized by the change of intensity and spectral composition of light. By changing the illumination and other lighting characteristics, it is possible to get the necessary lighting effect for the functional purpose of a particular visual environment.

Mood is a temporary state of mind or feeling (Mood, n. d.). "Mood is relatively long lasting emotional state or quality of feeling at a particular time" (CTI Reviews, 2017). Simultaneously with visual effects, a certain number and representation of colour and light also influences the mood. It is proved that on a sunny day we feel much better than in bad weather. In daylight time, we are more active than being exposed to artificial lighting. Our body reacts to the changes of light, its colour and quantity, time of the day, season and weather conditions.

The sense of safety is a basic human emotion, when the effect of external and internal factors does not lead to unacceptable state, deterioration in the functioning and development of the organism, consciousness, psyche and the person as a whole, and does not disturb the achievement of certain desirable human purposes.

Comfort. Results show that studies refer to comfort (a pleasant feeling of being relaxed) as one of the most important emotional effects of lighting quality parameters and characteristics in emotional impact on humans. The dynamics of artificial lighting could be regarded as one of the ways to create favourable microclimate of visual environment. It can compensate the lack or shortage of natural illumination. The flexibility of artificial lighting can be achieved through the regulation of the light flow and the use of various lighting devices.

Physical effect consists of the following parameters mentioned in the analyzed materials:

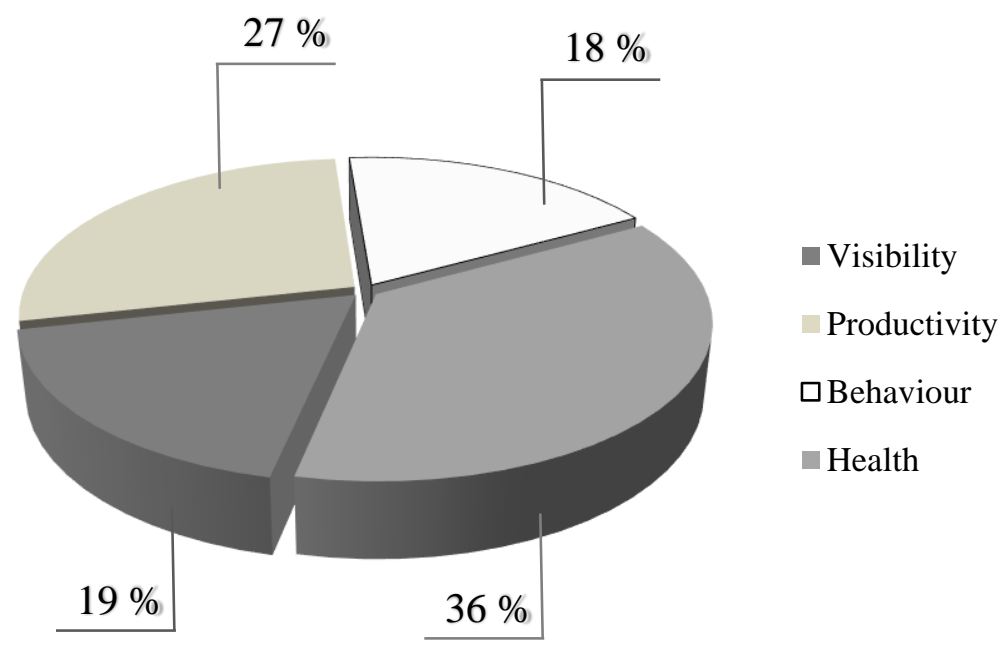

Fig. 3. Ratio of references to the physical effects of lighting such as visibility, productivity, behaviour and health in the reviewed studies.

Visibility is the state of being able to see or be seen (Visibility, n. d.). "Visual perception is the ability to interpret the surrounding environment using light in the 
visible spectrum reflected by the objects in the environment" (Livingstone \& Hubel, 2008).

Productivity is "the effectiveness of productive effort, especially in industry, as measured in terms of the rate of output per unit of input." (Productivity, n. d.). Productivity describes characteristics of human behaviour, which serves for the purpose of development and improvement of personal well-being and the prosperity of the related groups.

Behaviour is the way in which one acts or conducts oneself, especially towards others (Behaviour, n. d.). Behaviour is a set of consistently performed actions that secures practical contact of the individual with surroundings, in accordance with properties of the environment, ensuring the achievement of certain goals. Great number of people does not realize that they become irritable or even angry in their workplace because of poor lighting as this is not always obvious.

Health. Results show that discussing lighting quality parameters and characteristics researchers more often refer to health as one of the most important physical effects on humans, which is the level of functional and metabolic efficiency of a living organism (human in particular case). It should be considered by the developers and planners of real estate projects in the course of panning of visual environment and lighting systems. Answering the question what is the most important thing in life most people respond that it is health. There is a lot of information about healthy nutrition, fitness and ecology, and these issues are widely covered in newspapers, magazines and web pages, but the issues of correct and healthy lighting are not described in great detail.

\section{CONCLUSION}

Analyzed materials focus on different aspects of qualitative parameters and characteristics of lighting, but at the same time refer to different aspects of the impact on humans. The aspects mentioned can be split into two major groups: aspects of physical and emotional effect.

Physical effect is any consequence of some cause which is related to the material world.

Emotional effect is a relatively short physiological process, motivating and regulating activity, reflecting the subjective significance of objects and situations, and represented in the form of experience.

The analyzed studies mainly refer to the emotional effect of lighting quality parameters and characteristics on humans in different visual environments, which means that lighting quality parameters have an important influence on the emotions of humans. Scientific studies show that lighting is an essential part of visual environment planning. Lighting settings and quality parameters should be taken into consideration and assessed during the evaluation of visual environment of real estate or urban development projects. The methodology of evaluation needs to be developed in the process of further research. 


\section{REFERENCES}

Wunsch, A. (2006). Artificial Lighting and Health. Journal of Optometric Phototherapy, April, 1-5.

Behaviour. (n. d.). In Oxford dictionaries. Retrieved November 2, 2017, from https://en.oxforddictionaries.com/definition/behaviour

CTI Reviews. (2017). Experience Psychology, Cram101 Textbook Reviews, 2017. ISBN 1497054699, 9781497054691.

licht.wissen 01. Lighting with Artificial Light [Booklet]. (2016). Frankfurt am Main: Fördergemeinschaft Gutes Licht.

Ganslandt, R., \& Hofmann, H. (1992). Handbook of Lighting Design. Verlag Vieweg. ISBN 3528088958

Ott, J. N. (1973). Health and Light. Alpharetta, GA, United States: Alliance Press. ISBN 139780898040982

Livingstone, M, \& Hubel, D. H. (2008). Vision and art: the biology of seeing, New York: Abrams. ISBN 978081099554.

Mood. (n. d.). In Oxford dictionaries. Retrieved November 2, 2017, from https://en.oxforddictionaries.com/definition/mood

Rosenthal, N. E., Sack, D. A., Gillin, J. C., Lewy, A. J., Goodwin, F. K., Davenport, Y., Mueller, P. S., Newsome, D. A., \& Wehr, T. A. (1984). Seasonal Affective Disorder. Archives of General Psychiatry, 41(1), 72-80. https://doi.org/10.1001/archpsyc.1984.01790120076010

Perception. (n. d.). In Oxford dictionaries. Retrieved November 2, 2017, from https://en.oxforddictionaries.com/definition/perception

Productivity. (n. d.). In Oxford dictionaries. Retrieved November 2, 2017, from https://en.oxforddictionaries.com/definition/productivity

Visibility. (n. d.). In Oxford dictionaries. Retrieved November 2, 2017, from https://en.oxforddictionaries.com/definition/visibility

\section{AUTHORS' SHORT BIOGRAPHIES}

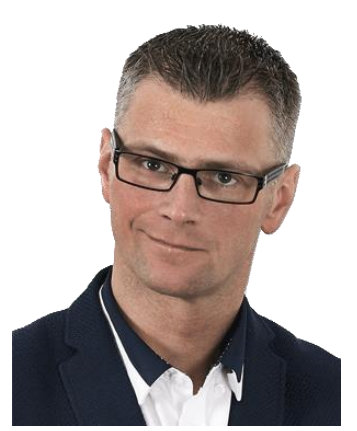

N̦ikita Kočanovs is a $\mathrm{PhD}$ Student of the Faculty of Engineering Economics and Management, Scientific Assistant, Lecturer at Riga Technical University, Latvia. He holds a Master Degree in Electrical Engineering from Riga Technical University, MBA degree from the Baltic International Academy, Master of Arts in Architectural Lighting Design and Design Management from Wismar University of Applied Sciences, Technology, Business and Design. His current research areas are planning of visual environment in real estate projects, architecture, lighting design, real estate development and management. Nikita Kocanovs is an active practitioner in engineering, construction and real estate business with more than 15 years of experience on the Latvian and Scandinavian markets. He has improved his professional skills in Germany, Sweden, Singapore.

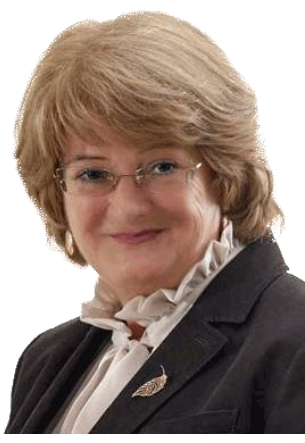

Raja Kočanova is Dr. sc. admin., researcher and Assistant Professor at Riga Technical University. She has long-term practical experience in the implementation of the Latvian national sustainability projects. Research interests: business strategic management, problems of sustainability of real estate market development, construction industry and institutional economics. Raja Kocanova is an author and co-author of more than 20 scientific publications. She has developed and published a scientific monograph that is dedicated to ensuring sustainable development of the strategic management problems of the company. She is an active participant in scientific conferences, congresses and workshops. 


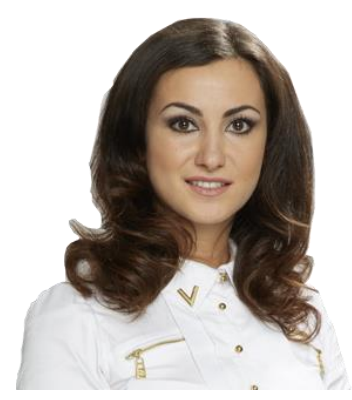

Olesja Bogodistaja is the Head of International Brokerage Service Department in Arco Real Estate Ltd. Her experience in real estate is more than 10 years. She holds a Bachelor degree from International High School of Practical Psychology and MBA degree in Innovations and Entrepreneurship from Riga Technical University. The main field of her activities is high and luxury segment of real estate, work with non-residents and residence permit in Latvia. She is an author of various articles, interviews and press releases about the real estate market and residence permit in Latvia. 